\title{
Sestina: People's Republic of China, the Foreign Woman Laments the Revolution's Failure to Accomodate Love $\cdot$ Marilyn Krysl
}

You're married. So is everyone else Chinese.

How odd, a billion people done up in couples.

You never see no flirty eyes let fly a dazzle. A place for every piece (please excuse my profanity) and every piece in place. "We cannot have the people going crazy!"

Imagine Mao saying this to Zhou. Crazy as a loon, I moon, imagining your Chinese face eyes hands. I live on looks, no place for assignation. What happens here to couples is they marry. Until which time (please, don't touch) they burn. No one gets high, flies

to Jamaica, makes it. No one gets high. They fly to Canton, work at the Trade Fair. Work. Craziness is a luxury only capitalists can afford. Please remember Mrs. Marcos' three hundred suitcases! The Chinese have more sense and fewer resources. A couple strolls by our bench, keeping their hands in place-

in their pockets. We meet in Renmin Park, no place to meet. The great outdoors! Up the geese fly, avoiding this frozen lake, these shivering couples. Circumspect, we talk. Only our eyes go crazy, we're decorous beyond belief. How Chinese I feel, repressing my feeling. Pretending pleases

the patriarchal we, stabilizes stability. I please no one but all society, that monolithic place where no one resides (not me, not a single Chinese), and order prevails. Except that there's always a fly in the ointment. Love raising its crazy head, demanding lectures on Freud_-and a couple 
of days ago a student kissed me. A couple

of decades from now you and I may meet (please

bring champagne, forget Confucius), go crazy

in Singapore, Tahiti, Mexico City, some place

where you can get a private room, fly

in the face of the Nineteenth Century. Meanwhile the Chinese

coast is not clear. Couples, please take your place

in line. Forget propinquity, sublimate like crazy.

Good friend, I'm not Chinese and I must fly. 